\title{
Improving Mechanical Properties of Mg-Sc Alloy by Surface AZ31 Layer
}

\author{
Cheng Zhang ${ }^{1,2}$, Cheng Peng ${ }^{1, *}$, Jin Huang ${ }^{2,3, * \mathbb{D}}$, Yanchun Zhao ${ }^{1}$, Tingzhuang Han ${ }^{4}$, Guangang Wang ${ }^{5}$, \\ Liang $\mathrm{Wu}^{5} \mathbb{D}$ and Guangsheng Huang ${ }^{5}$
}

1 The Key Laboratory of Chongqing Inorganic Special Functional Materials, Yangtze Normal University, Chongqing 408100, China; zhangcheng@cqu.edu.cn (C.Z.); yczhao@yznu.edu.cn (Y.Z.)

2 School of Chemistry and Chemical Engineering, Chongqing Key Laboratory of Soft-Matter Material Chemistry and Function Manufacturing, "The Belt and Road (B\&R)" International Joint Research Laboratory of Sustainable Materials, Southwest University, Chongqing 400715, China

3 School of Chemistry and Chemical Engineering, Engineering Research Center of Materials-Oriented Chemical Engineering of Xinjiang Bintuan, Shihezi University, Shihezi 832003, China

4 State Key Laboratory of Solidification Processing, School of Materials Science \& Engineering, Northwestern Polytechnical University, Xi'an 710072, China; htzhhbhs@163.com

5 State Key Laboratory of Mechanical Transmission, College of Materials Science and Engineering, Chongqing University, Chongqing 400044, China; ggwang@nchu.edu.cn (G.W.); wuliang@cqu.edu.cn (L.W.); gshuang@cqu.edu.cn (G.H.)

* Correspondence: pc20090008@163.com (C.P.); huangjin2015@swu.edu.cn (J.H.)

check for updates

Citation: Zhang, C.; Peng, C.;

Huang, J.; Zhao, Y.; Han, T.; Wang, G.; Wu, L.; Huang, G. Improving Mechanical Properties of Mg-Sc Alloy by Surface AZ31 Layer. Metals 2021, 11, 2021. https://doi.org/10.3390/ met11122021

Academic Editor: Frank Czerwinski

Received: 13 November 2021

Accepted: 7 December 2021

Published: 14 December 2021

Publisher's Note: MDPI stays neutral with regard to jurisdictional claims in published maps and institutional affiliations.

Copyright: (C) 2021 by the authors. Licensee MDPI, Basel, Switzerland. This article is an open access article distributed under the terms and conditions of the Creative Commons Attribution (CC BY) license (https:// creativecommons.org/licenses/by/ $4.0 /)$.

\begin{abstract}
Building a gradient structure inside the $\mathrm{Mg}$ alloy structure can be expected to greatly improve its comprehensive mechanical properties. In this study, AZ31/Mg-Sc laminated composites with gradient grain structure were prepared by hot extrusion. The microstructure and mechanical properties of the Mg-1Sc alloy with different extrusion temperatures and surface AZ31 fine-grain layers were investigated. The alloy has a more obvious gradient microstructure when extruded at $350{ }^{\circ} \mathrm{C}$. The nanoscale hardness value of $\mathrm{Mg}-1 \mathrm{Sc}$ alloy was improved through fine-grain strengthening and solution strengthening of the surface AZ31 fine-grain layer. The strength of $\mathrm{Mg}-1 \mathrm{Sc}$ alloy was improved due to the fine-grain strengthening and dislocation strengthening of the surface AZ31 fine-grain layer, and the elongation of $\mathrm{Mg}-1 \mathrm{Sc}$ alloy was increased by improving the distribution of the microstructure.
\end{abstract}

Keywords: Mg-Sc alloy; AZ31; composites; microstructure; mechanical properties

\section{Introduction}

Magnesium (Mg) alloys have the advantages of low density, high specific strength, good damping capacity, machinability, and retrievability, which have broad application prospects in the fields of transportation, aerospace, the military industry, and so on [1-4]. However, due to the close-packed hexagonal crystal structure of $\mathrm{Mg}$ alloys, insufficient slipping systems can be activated at lower temperatures, resulting in poor ductility and low strength [5,6]. Therefore, in order to improve their mechanical properties, much research work has been carried out.

The mechanical properties of $\mathrm{Mg}$ alloys depend on grain size and orientation to a great extent. Controlling texture and refining the grain by proper processing technology is an important method to improve the mechanical properties of $\mathrm{Mg}$ alloys [7]. Grain refinement can improve the strength of $\mathrm{Mg}$ alloys obviously, but the ductility of $\mathrm{Mg}$ alloys is sacrificed to some extent, so that the relationship between strength and ductility is always inverted [8]. Previous studies [9,10] showed that the introduction of a gradient structure in metal materials can break the original coupled material properties and allow one or more properties to be improved independently, which provides a new idea and development direction for the preparation of high strength and high ductility materials. 
Researchers [10-13] have successfully prepared surface nanocrystalline/ultra-fine core coarse-grained gradient structure materials using surface mechanical attrition treatment (SMAT), surface mechanical grinding treatment (SMGT), ultrasonic shot peening (USSP), and high-energy shot peening (HESP). The strength of the materials has been significantly improved, and the elongation has not been significantly decreased. Chen et al. [14] studied the influence of SMAT technology on the mechanical properties of AZ31 Mg alloy sheets and found that the tensile yield strength of the alloy was about four times higher than that of the coarse-grained samples, and the elongation was only slightly reduced. Peng et al. [15] also prepared AZ31 Mg alloy plates with good strength and plasticity matching (yield strength $\sim 250 \mathrm{MPa}$ and elongation $\sim 17 \%$ ) through SMAT technology. Jamalian et al. [16] obtained the AZ31 Mg alloy sheet with a gradient structure of superfine grains on the surface and coarse grains at the core by shot peening. The yield strength and tensile strength were significantly improved and there would have been a certain degree of plastic loss, but the lost ductility can be restored by annealing. Therefore, this is a new way to improve the comprehensive properties and construct the gradient grain structure of the material.

As a light rare earth element with high melting point, scandium (Sc) has unique physical and chemical properties, such as high solid solubility in $\mathrm{Mg}$ and similar lattice parameters with $\mathrm{Mg}$, which has great research value [17]. A small amount of research [18-20] on the high temperature creep, mechanical, and corrosion properties of $\mathrm{Mg}-\mathrm{Sc}$ alloy has been reported. Besides this, AZ31 Mg alloy is widely used commercially at present and has good mechanical properties. Therefore, the gradient grain structure containing AZ31 alloy was prepared on the surface of $\mathrm{Mg}-\mathrm{Sc}$ alloy by a hot extrusion method in this paper. The effect of different extrusion temperatures on the microstructure of the alloys was characterized, and the effect of a fine-grained surface layer of AZ31 on the mechanical properties of $\mathrm{Mg}-\mathrm{Sc}$ alloy was investigated.

\section{Materials and Methods}

\subsection{Materials}

A Mg-1.0 wt.\% Sc (Mg-1Sc) alloy ingot was prepared from pure $\mathrm{Mg}$ and $\mathrm{Mg}-10 \mathrm{wt} . \%$ $\mathrm{Sc}$, and $\mathrm{AZ} 31$ alloy ingots were prepared from pure $\mathrm{Mg}, \mathrm{Al}, \mathrm{Zn}$, and $\mathrm{Mg}-10 \mathrm{wt} . \% \mathrm{Mn}$ master alloys by an induction melting furnace under the protection of $\mathrm{CO}_{2}+\mathrm{SF}_{6}$ atmosphere. The ingots were homogenized at $400{ }^{\circ} \mathrm{C}$ for $24 \mathrm{~h}$ and the ingots were air-cooled. The as-cast AZ31 alloy was firstly extruded as plates of $2 \mathrm{~mm}$ at $320^{\circ} \mathrm{C}$ (or $350{ }^{\circ} \mathrm{C}$ ) with an extrusion ratio of 50.6. At this time, part of the AZ31 alloy remained in the extrusion cylinder. Subsequently, the $\mathrm{Mg}-\mathrm{Sc}$ alloy was extruded under the same conditions. Since the high temperature hardness of AZ31 alloy is much higher than that of $\mathrm{Mg}-\mathrm{Sc}$ binary alloy, during the extrusion process of the Mg-Sc alloy AZ31 alloy adhered to the surface of the $\mathrm{Mg}-\mathrm{Sc}$ alloy, forming the Mg-Sc alloy with AZ31 alloy on both upper and lower surfaces. After several extrusion tests at different temperatures, it was found that the surface quality of the sheet was better when extruded at $320^{\circ} \mathrm{C}$ and $350{ }^{\circ} \mathrm{C}$, without edge cracks, and the AZ31 sheet could adhere to the surface of the $\mathrm{Mg}-\mathrm{Sc}$ alloy. Therefore, these two extrusion temperatures were selected. The schematic diagram of the extrusion processes is shown in Figure 1. The Mg-Sc alloys (MS) were defined as MS-320 and MS-350 with an extrusion temperature of $320^{\circ} \mathrm{C}$ and $350^{\circ} \mathrm{C}$, respectively. The $\mathrm{Mg}-\mathrm{Sc}$ alloys with an AZ31 surface layer (MSAZ) were defined as MSAZ-320 and MSAZ-350 with extrusion temperature of $320{ }^{\circ} \mathrm{C}$ and $350{ }^{\circ} \mathrm{C}$, respectively. The actual chemical composition of the alloys was detected using a plasma-atomic emission spectrometer (ICP-AES) and the results are given in Table 1. 


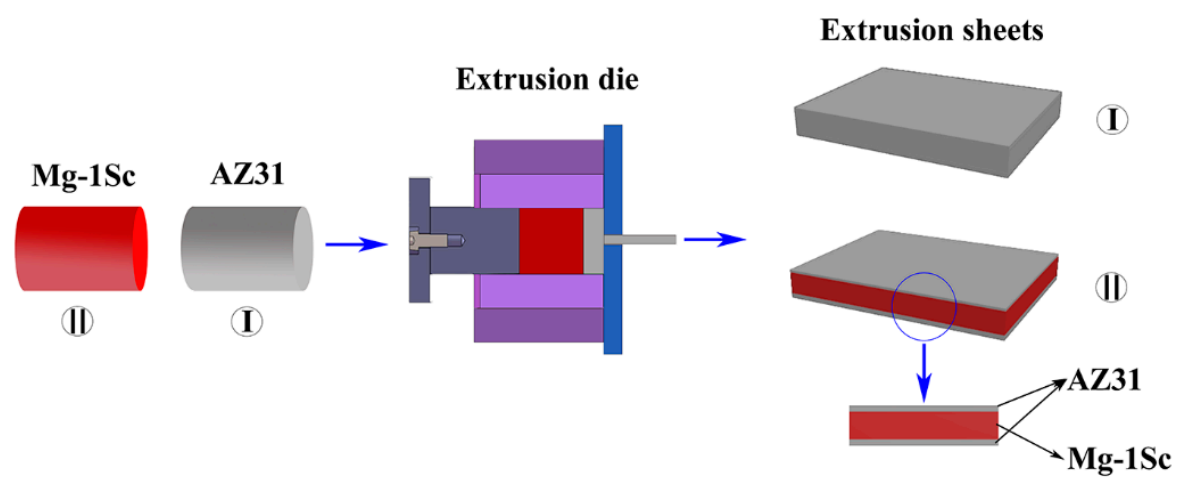

Figure 1. The schematic diagram of the extrusion processes.

Table 1. Chemical composition of Mg-1Sc and AZ31 alloys (wt.\%).

\begin{tabular}{cccccc}
\hline Alloys & Sc & Al & Zn & Mn & Mg \\
\hline Mg-1Sc & 1.05 & - & - & - & Bal. \\
AZ31 & - & 3.22 & 0.94 & 0.37 & Bal. \\
\hline
\end{tabular}

\subsection{Microstructure Characterization}

$\mathrm{X}$-ray diffraction $(\mathrm{XRD})$ was performed to identify the phase precipitated in the alloys at a glancing angle of $1.5^{\circ}$ using a $\mathrm{Cu}$ target $(40 \mathrm{kV}, 150 \mathrm{~mA})$, within the range of $2 \theta=10-90^{\circ}$ and at a scanning rate of $4^{\circ} \mathrm{min}^{-1}$. Optical microscopy (OM) was performed for optical grain size observations. Specimens were firstly polished by $\mathrm{SiC}$ paper and were then etched with a solution composed of $14 \mathrm{~mL}$ ethanol, $2 \mathrm{~mL}$ acetic acid, and $2.5 \mathrm{~g}$ picric acid to reveal the grain boundaries. Electron backscatter diffraction (EBSD) was performed on a JEOL JSM-7800F (JEOL, Tokyo, Japan) for microstructure characterization. Specimens were mechanically polished with 4000\# $\mathrm{SiC}$ paper and electropolished in an AC2 solution $(800 \mathrm{~mL}$ ethanol $+100 \mathrm{~mL}$ propanol $+18.5 \mathrm{~mL}$ distilled water $+10 \mathrm{~g}$ hydroxyquinoline + $75 \mathrm{~g}$ citric acid $+41.5 \mathrm{~g}$ sodium thiocyanate $+15 \mathrm{~mL}$ perchloric acid) at $20 \mathrm{~V}$ for $2 \mathrm{~min}$ at $-20{ }^{\circ} \mathrm{C}$. The EBSD experiments were accomplished at $25 \mathrm{kV}$ with a step size of $0.5 \mu \mathrm{m}$.

\subsection{Hardness and Tensile Tests}

The nanoindentation behavior was investigated using the Agilent G200 (Agilent, Santa Clara, CA, USA) and Hysitron TI950 (Hysitron, Minneapolis, MN, USA). The extrusion direction-transverse direction (ED-TD) plane of the specimens was detected with a compression depth of $300 \mathrm{~nm}$ at $20 \pm 2{ }^{\circ} \mathrm{C}$. The specimens with dimensions of $10 \times 10 \times 2 \mathrm{~mm}^{3}$ were prepared by mechanical polishing with $\mathrm{SiC}$ paper, followed by polishing by $\mathrm{w} 0.25$ diamond polishing agent. Tensile specimens were prepared from the extruded sheets along the ED, with a $24 \mathrm{~mm}$ gauge length, and a $4 \mathrm{~mm}$ gauge width. The tensile tests were carried out on a uniaxial tensile testing machine (SUST, Zhuhai, China) at an initial strain rate of $10^{-3} \mathrm{~s}^{-1}$ at ambient temperature, and three parallel specimens were used to obtain representative results.

\section{Results}

\subsection{Microstructure Characterization}

Figure 2 shows XRD patterns of the MS and MSAZ alloys. There was only a peak of $\alpha-\mathrm{Mg}$ in the four alloys without a peak of the second phase, indicating that the alloys under various conditions have very little or no second phase. As such, to a great extent, the mechanical properties of the alloys are determined by the $\alpha$-Mg matrix phase. 


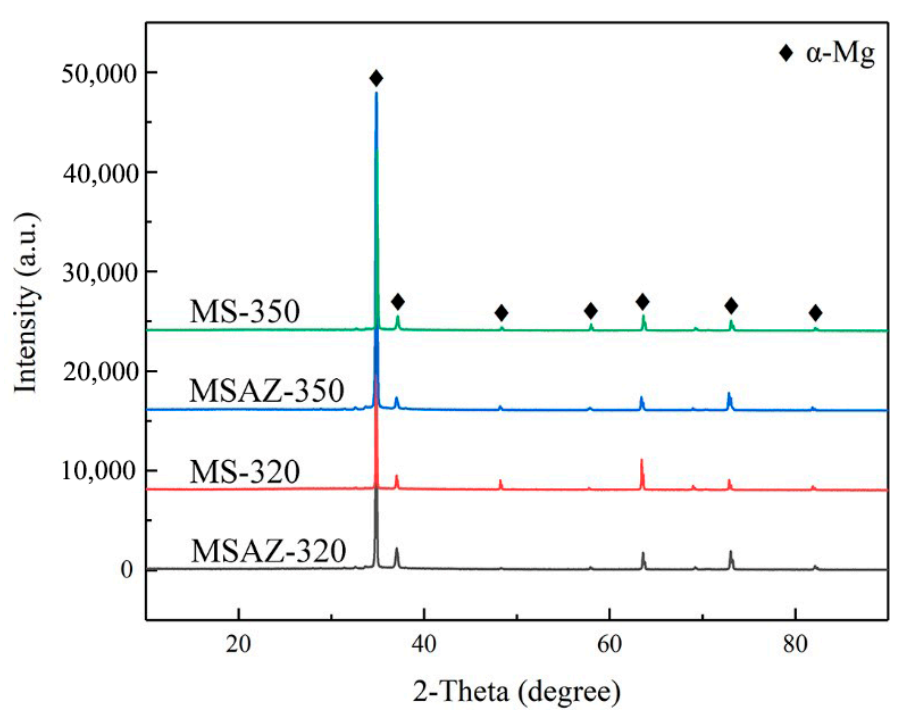

Figure 2. XRD patterns of the MS and MSAZ alloys.

Figure 3 shows the optical microstructure of MSAZ-320 and MSAZ-350 alloys. The AZ31 alloy adhered to the surface of the $\mathrm{Mg}-\mathrm{Sc}$ alloy to form a composite alloy in the process of hot extrusion at $320^{\circ} \mathrm{C}$ or $350^{\circ} \mathrm{C}$. At the two different extrusion temperatures, abnormal coarse AZ31 grains appeared on the topmost surface of the alloy. This is because the deformation of the topmost surface was large and the storage energy was the highest during extrusion, which resulted in abnormal grain growth during extrusion and subsequent cooling. When extruded at $320^{\circ} \mathrm{C}$, the coarse grain layer of AZ31 is about $70 \mu \mathrm{m}$. When extruded at $350{ }^{\circ} \mathrm{C}$, the surface AZ31 coarse-grain layer is about $25 \mu \mathrm{m}$. The lower extrusion temperature made the pressure in the extrusion cylinder larger and the deformation of the top layer of the alloy larger. Therefore, when the extrusion temperature is $320^{\circ} \mathrm{C}$, a thick and abnormally coarse grain structure was produced. It is worth noting that the AZ31 fine-grain layer appeared on the surface of the Mg-Sc alloys at both extrusion temperatures. When extruded at $320^{\circ} \mathrm{C}$, the AZ31 fine-grain layer on the surface was about $150 \mu \mathrm{m}$, and when extruded at $350{ }^{\circ} \mathrm{C}$, the AZ31 fine-grain layer on the surface was about $120 \mu \mathrm{m}$.

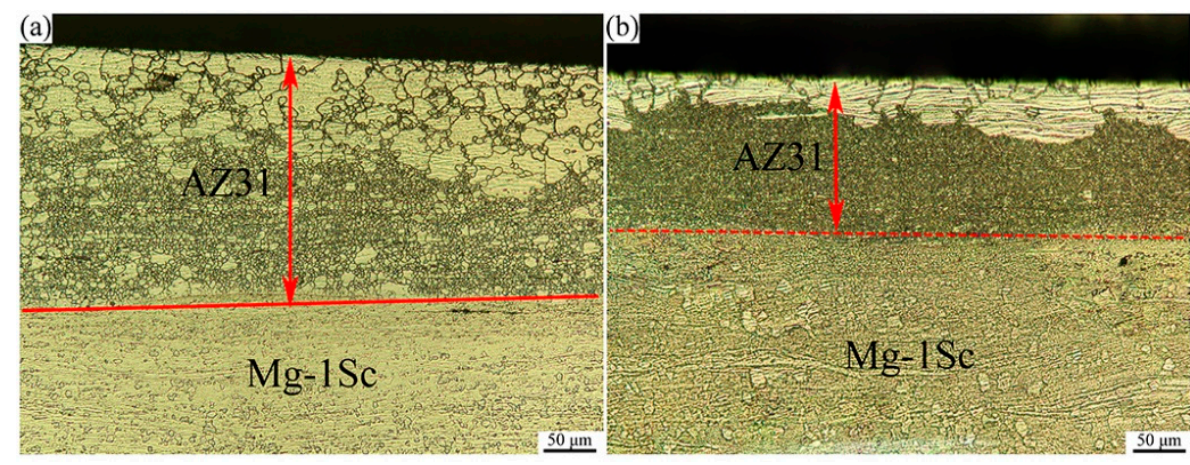

Figure 3. Optical microstructure of (a) MSAZ-320 and (b) MSAZ-350 alloys.

Figures 4 and 5 show the microstructure and corresponding energy dispersive $X$ ray spectroscopy (EDS) mapping of the transition region of MSAZ-320 and MSAZ-350, respectively. It is interesting that there was a transition layer between the surface AZ31 and the core Mg-Sc alloy in both two alloys. According to the results of EDS, the transition layer of the two alloys was the $\mathrm{Mg}-\mathrm{Sc}$ alloy and the thickness was about $30 \mu \mathrm{m}$. At two extrusion temperatures, the grain size of the $\mathrm{Mg}-\mathrm{Sc}$ alloy in the transition layer is obviously different from that in the core region, especially at $350{ }^{\circ} \mathrm{C}$. It is worth noting that the grain 
size between these two regions is not a gradual change, but rather a sudden change in grain size.

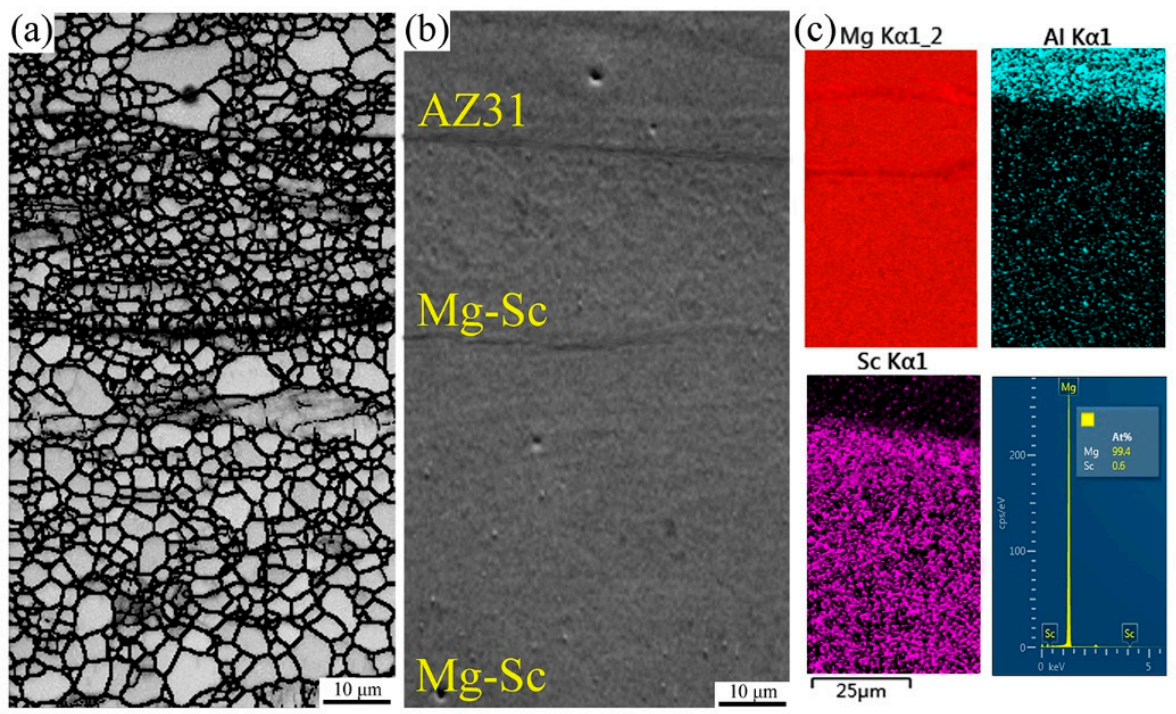

Figure 4. (a,b) Microstructure and (c) corresponding EDS mapping of the transition region of MSAZ-320.

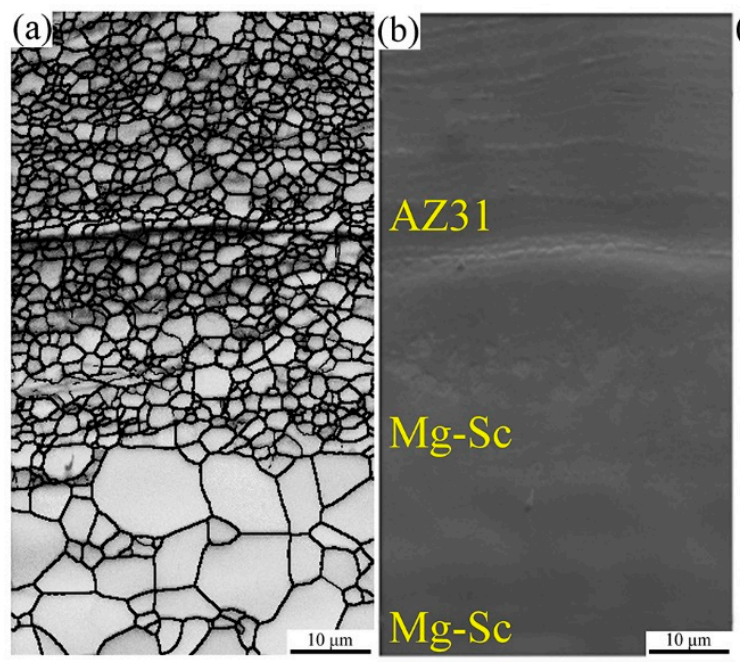

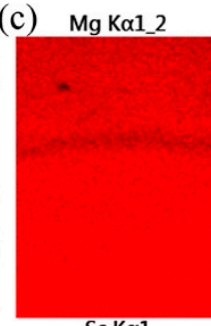

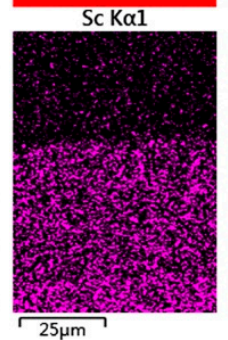

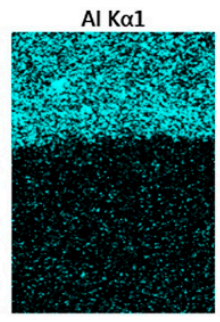

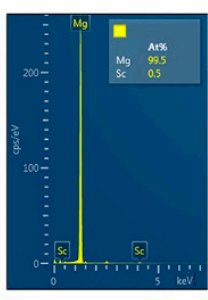

Figure 5. $(\mathbf{a}, \mathbf{b})$ Microstructure and (c) corresponding EDS mapping of the transition region of MSAZ-350.

To obtain more accurate statistics on the grain size of the three different regions, EBSD data of the three regions of the two alloys were collected in a certain area. Figure 6 shows the microstructure and statistical histogram of the grain size of MSAZ-320 and MSAZ-350. The equiaxed grains with relatively uniform size were observed in the three different regions of MSAZ-320 and MSAZ-350. When the extrusion temperature was $320^{\circ} \mathrm{C}$, the difference between the grain size of the AZ31 fine-grain layer and the $\mathrm{Mg}-\mathrm{Sc}$ transition layer was small, and the grain size of the former was slightly larger than that of the latter, which was also caused by the larger deformation and higher storage energy of the surface layer when the extrusion temperature was $320^{\circ} \mathrm{C}$. Similarly, the grain size of the $\mathrm{Mg}-\mathrm{Sc}$ region in the core was higher than that in the transition layer. When the extrusion temperature was $350{ }^{\circ} \mathrm{C}$, the grain size of the three regions showed a gradient increasing trend. With the increase in extrusion temperature, the difference of grain size of the two alloys between the $\mathrm{Mg}-\mathrm{Sc}$ transition layer was not significant, but the grain size difference 
between the core of $\mathrm{Mg}-\mathrm{Sc}$ alloy was great. The average grain size (AG) of the core of MSAZ-350 $(5.05 \mu \mathrm{m})$ was about twice that of the core of MSAZ-320 $(2.51 \mu \mathrm{m})$.

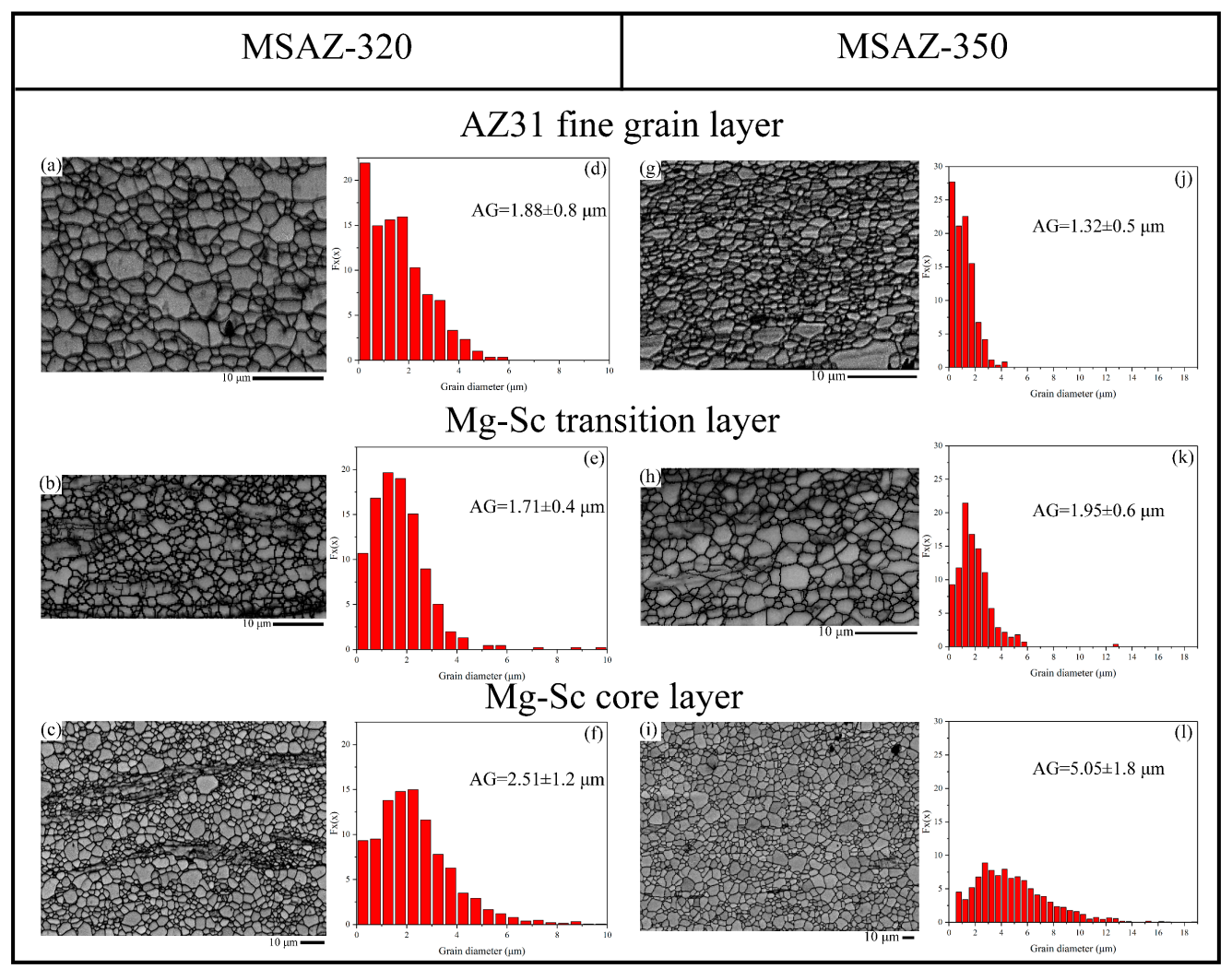

Figure 6. $(\mathbf{a}-\mathbf{c})$ Microstructure and $(\mathbf{d}-\mathbf{f})$ grain size distribution of the corresponding surface finegrain layer, transition layer, and core layer of MSAZ-320. ( $\mathbf{g}-\mathbf{i})$ Microstructure and (j-l) grain size distribution of the corresponding surface fine-grain layer, transition layer, and core layer of MSAZ-350.

Figure 7 shows the inverse pole figures (IPF) and pole figures corresponding to the three regions of MSAZ-320. The surface AZ31 region of MSAZ-320 presented a strong basal texture with the maximum strength of 33.81, and the basal planes of most grains were parallel to the ED-TD plane of the sheet. Compared with the surface AZ31 fine-grain layer, the texture of the $\mathrm{Mg}-\mathrm{Sc}$ transition layer was deflected from normal direction (ND) to ED and TD, and the texture was more divergent, with an intensity of 9.37. The texture in the $\mathrm{Mg}-\mathrm{Sc}$ core layer still deflected from ND to ED and TD, and the texture strength was smaller than that in the transition layer, which was 8.61. In other words, the texture of MSAZ-320 gradually diverged from the surface to the center, showing a trend of gradually decreasing the texture strength. Figure 8 shows IPF and pole figures corresponding to the three regions of MSAZ-350. Similarly, the surface AZ31 fine-grain layer of MSAZ-350 also presented a strong basal texture, the maximum strength of which was 46.85 , and the basal planes of almost all grains were parallel to the ED-TD plane of the sheet. The texture of the $\mathrm{Mg}-\mathrm{Sc}$ transition layer also deflected from $\mathrm{Nd}$ to ED and TD, with an intensity of 13.16. The texture strength of the Mg-Sc core layer was 9.20. The texture strength of the MSAZ-350 alloy also decreased gradually from the surface to the center. The texture strength of each region of MSAZ-350 was higher than MSAZ-320. Figure 9 shows IPF and pole figures of the transition region of the two alloys, and also represents the fact that the texture strength of the transition region of MSAZ-350 alloy was higher than that of MSAZ-320. 

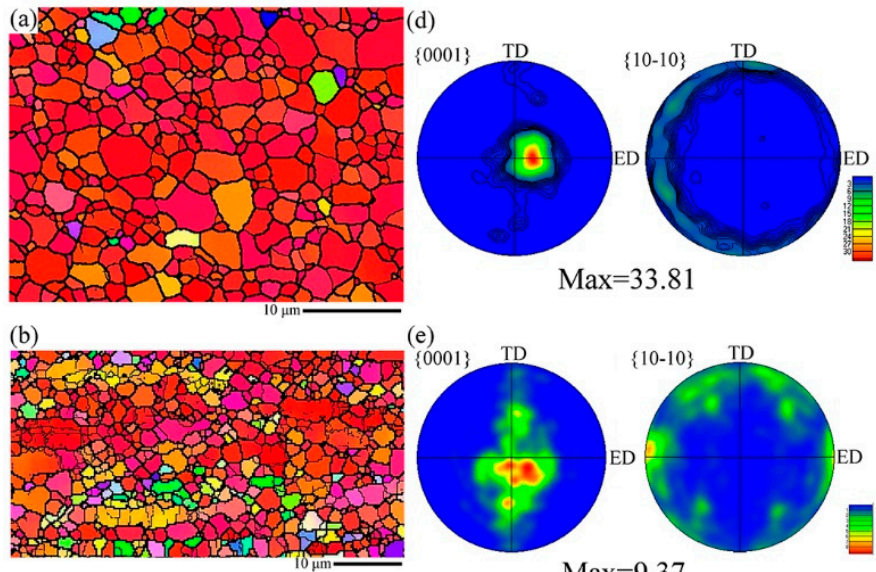

$\operatorname{Max}=9.37$
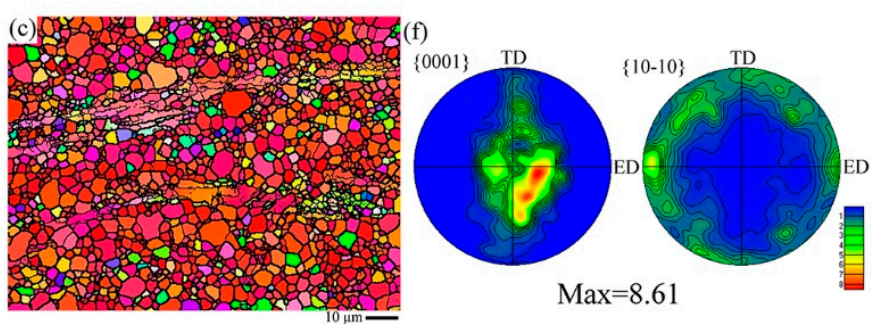

$\operatorname{Max}=8.61$

Figure 7. (a) EBSD inverse pole figures and (d) (0001) and (10-10) pole figures of AZ31surface finegrain layer, (b) EBSD inverse pole figures and (e) (0001) and (10-10) pole figures of $\mathrm{Mg}-\mathrm{Sc}$ transition layer, and (c) EBSD inverse pole figures and (f) (0001) and (10-10) pole figures of Mg-Sc core layer of MSAZ-320.
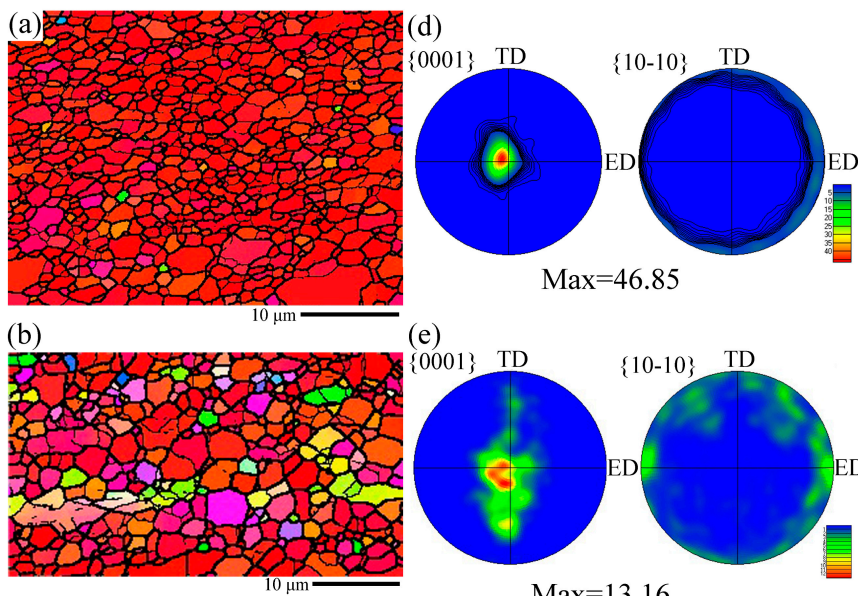

(e) $\{001\}$ TD $\quad\{10-10\} \quad T D$

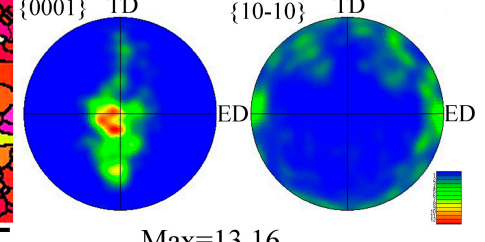

$\operatorname{Max}=13.16$

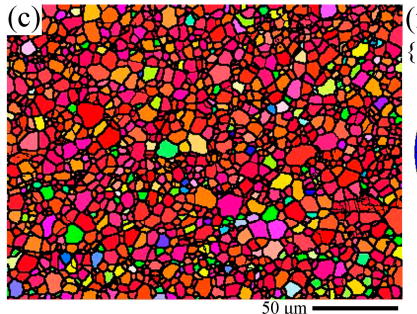

$(f)$

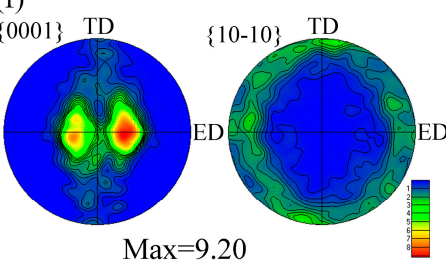

Figure 8. (a) EBSD inverse pole figures and (d) (0001) and (10-10) pole figures of AZ31surface finegrain layer, (b) EBSD inverse pole figures and (e) (0001) and (10-10) pole figures of $\mathrm{Mg}-\mathrm{Sc}$ transition layer, and (c) EBSD inverse pole figures and (f) (0001) and (10-10) pole figures of Mg-Sc core layer of MSAZ-350. 

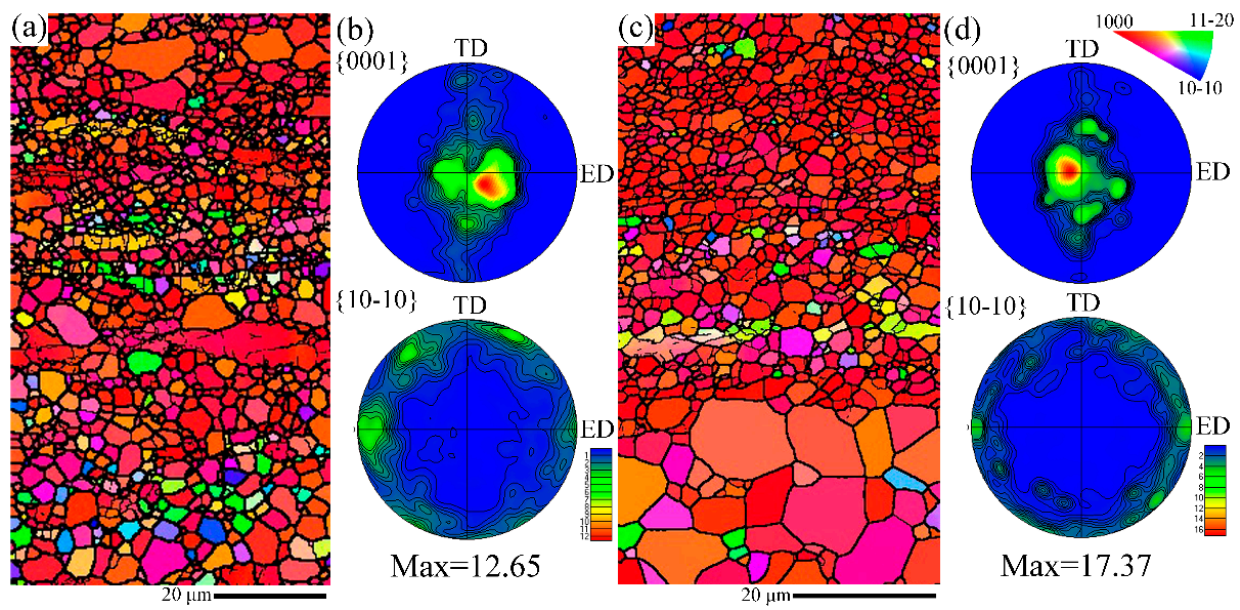

Figure 9. (a) EBSD inverse pole figures and (b) (0001) pole figures of MSAZ-320, and (c) EBSD inverse pole figures and (d) (0001) pole figures of transition region of MSAZ-350.

\subsection{Nanoindentation and Mechanical Properties}

Figure 10 shows hardness obtained by nanoindentation tests of the alloys in ED-TD planes with a compression depth of $300 \mathrm{~nm}$. The hardness values of the $\mathrm{Mg}-\mathrm{Sc}$ alloy sheets obtained at $320^{\circ} \mathrm{C}$ and $350{ }^{\circ} \mathrm{C}$ showed little difference. The hardness value of MS-320 was about $0.52 \mathrm{GPa}$ and that of MS-350 was about $0.47 \mathrm{GPa}$. Similarly, the hardness values of MSAZ-320 and MSAZ-350 were not significantly different, being about 1.08 GPa and $1.15 \mathrm{GPa}$, respectively. However, at the same extrusion temperature, whether there was AZ31 alloy on the surface of $\mathrm{Mg}-\mathrm{Sc}$ alloy or not resulted in a great difference. For example, when the extrusion temperature was $320^{\circ} \mathrm{C}$, the hardness value of the $\mathrm{Mg}-\mathrm{Sc}$ alloy with AZ31 alloy was about twice than that of the alloy without AZ31. As such, when the extrusion temperature was $350{ }^{\circ} \mathrm{C}$, the hardness value of the Mg-Sc alloy with AZ31 alloy was about twice than that of the alloy without AZ31. This indicates that the $\mathrm{Mg}-\mathrm{Sc}$ alloy surface composite AZ31 alloy was beneficial to improving the hardness value of the alloy.

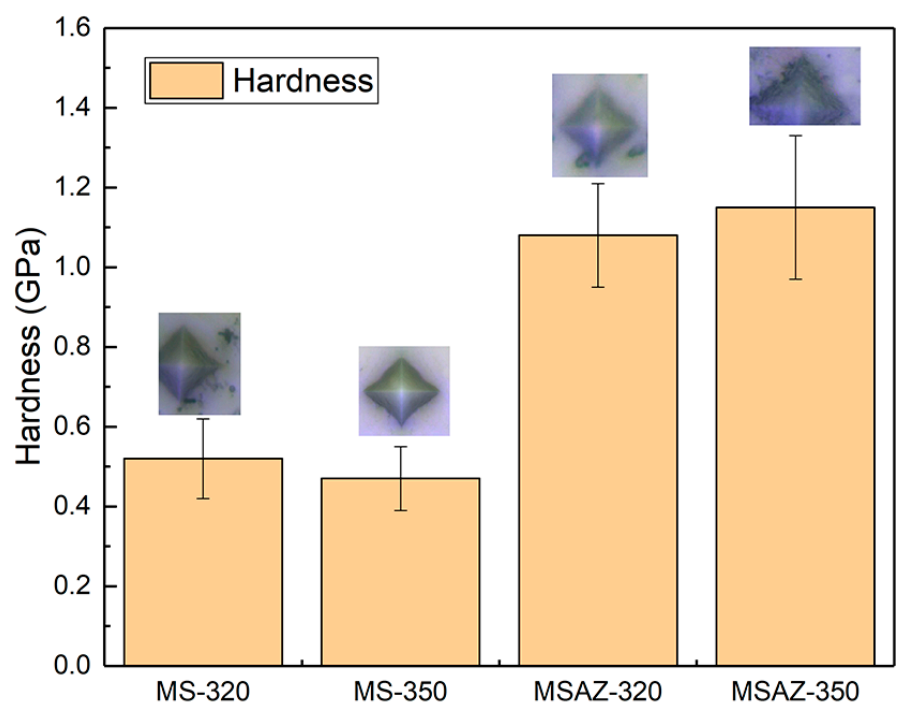

Figure 10. Hardness obtained by nanoindentation tests of the alloys.

Figure 11 shows true stress-strain curves and related mechanical properties of the alloys. At the two different extrusion temperatures, the tensile strength of the $\mathrm{Mg}-1 \mathrm{Sc}$ alloy sheet extruded at $320^{\circ} \mathrm{C}$ was $34 \mathrm{MPa}$ higher than that of the alloy extruded at $350^{\circ} \mathrm{C}$, but the elongation was $7.2 \%$ lower than that of the alloy extruded at $350^{\circ} \mathrm{C}$. For the $\mathrm{Mg}-1 \mathrm{Sc}$ alloy with AZ31 on the surface, when the extrusion temperature was $320^{\circ} \mathrm{C}$, the tensile 
strength of the alloy was $82 \mathrm{MPa}$ higher than that of the alloy extruded at $350{ }^{\circ} \mathrm{C}$, and the elongation was $3.8 \%$ lower than that of the alloy extruded at $350{ }^{\circ} \mathrm{C}$. That is, for the same alloy, the higher the extrusion temperature, the lower the tensile strength, but the higher the elongation. However, at the same extrusion temperature, both the tensile strength and elongation of $\mathrm{Mg}-1 \mathrm{Sc}$ alloys with AZ31 on the surface were higher than those of the Mg-1Sc alloys without AZ31. This indicates that the AZ31 composite on the Mg-1Sc alloy surface is not only beneficial to improving the tensile strength, but also to improving the elongation.
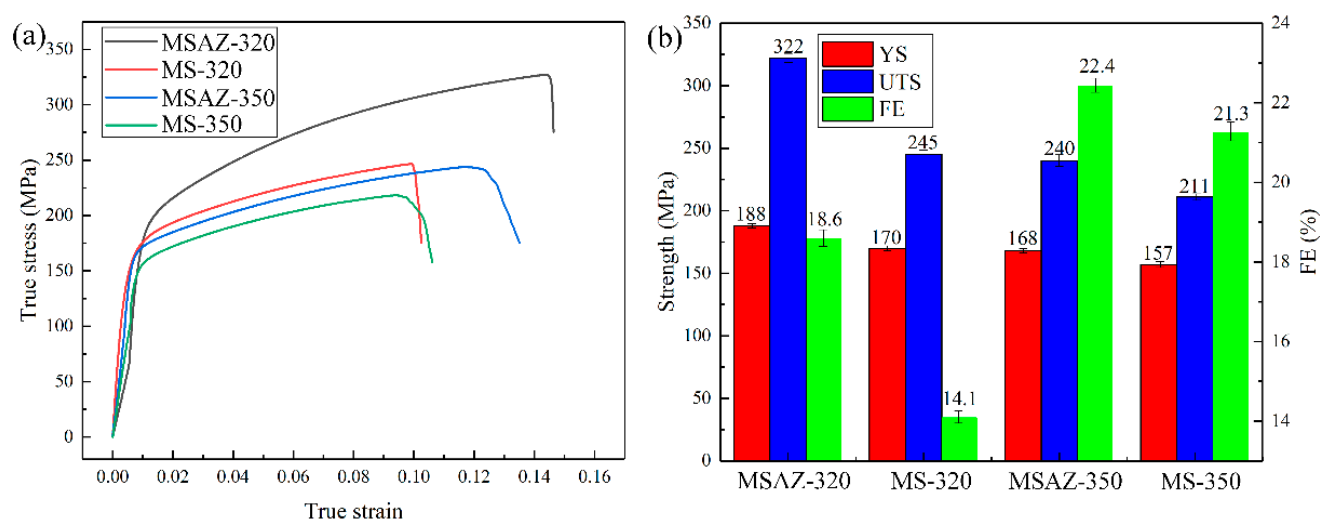

Figure 11. (a) True stress-strain curves and (b) corresponding mechanical properties of the alloys.

\section{Discussion}

\subsection{Effect of AZ31 Surface Fine Layer on Microstructure}

It can be seen from the microstructure figures (Figures 3-5) that the surface AZ31 and $\mathrm{Mg}-1 \mathrm{Sc}$ alloy are completely bonded and have good interfacial bonding quality. This represents a good metallurgical bond, mainly due to the large strain during the extrusion deformation process, which facilitates the bonding of the sheet interface [21]. When extruded at $320^{\circ} \mathrm{C}$, the thickness of AZ31 fine-grain layer on the surface is about $150 \mu \mathrm{m}$, and the thickness of AZ31 in the upper and lower layers accounts for $15 \%$ of the composition of the whole alloy. The grain size of the alloy increases from $1.88 \mu \mathrm{m}$ to $2.51 \mu \mathrm{m}$ from the surface region to the core region. When extruded at $350{ }^{\circ} \mathrm{C}$, the thickness of AZ31 fine-grain layer on the surface is about $120 \mu \mathrm{m}$, and the AZ31 on the upper and lower layers accounts for $12 \%$ of the composition of the whole alloy. The grain size of the alloy increases from $1.32 \mu \mathrm{m}$ to $5.05 \mu \mathrm{m}$ from the surface region to the core region. That is, the Mg-1Sc alloy and AZ31 composites with gradient structure were formed by the hot extrusion.

The dynamic recrystallization was found in the three regions of the two alloys in Figure 6. With the increase in extrusion temperature, the grains in the transition layer of $\mathrm{Mg}-1 \mathrm{Sc}$ grow slightly, and the grains in the core layer of $\mathrm{Mg}-1 \mathrm{Sc}$ grow obviously, while the grain size of AZ31 on the surface decreases. This is because when the extrusion temperature is lower and more deformation heat and friction heat are generated in the extrusion process, resulting in the static recrystallization of AZ31 on the surface under residual heat, finally leading to obvious grain growth on the surface [22]. With the increase of extrusion temperature, the grain size of the transition layer and core layer $\mathrm{Mg}-1 \mathrm{Sc}$ increases due to the increase in extrusion temperature which promotes the growth of recrystallized grain $[23,24]$.

\subsection{Effect of AZ31 Surface Fine Layer on Hardness}

According to the results of the hardness tests, the nano-indentation hardness value of MS-320 is slightly higher than that of MS-350. This is because when the extrusion temperature is low, the larger deformation degree of the alloy leads to the reduction of the grain size, and the fine grain size is conducive to the increase in the alloy hardness. When a layer of AZ31 alloy is bonded on the surface of Mg-1Sc alloy, its nano-hardness is 
significantly improved, because the grain size of AZ31 on the surface is small, and AZ31 alloy contains $\mathrm{Al}, \mathrm{Zn}, \mathrm{Mn}$, and other elements. The hardness value can be improved by grain refinement and solution strengthening $[25,26]$. In addition, the nano-hardness of MSAZ-350 is slightly higher than that of MSAZ-320, which is also related to the finer grain size on the surface of MSAZ-350. In short, due to the relatively coarse grain size of $\mathrm{Mg}-1 \mathrm{Sc}$ and the small variety and content of alloying elements in the alloy, it cannot play a good role in improving the hardness. The surface AZ31 with fine grain and solution strengthening effect is beneficial to improving the hardness value of $\mathrm{Mg}-1 \mathrm{Sc}$ alloy and expanding its application range.

\subsection{Mechanical Properties of the Alloys}

\subsubsection{Effect of Temperature on Mechanical Properties}

The strength of MS alloy and MSAZ alloy obtained at $320^{\circ} \mathrm{C}$ is higher than that of MS alloy and MSAZ alloy obtained at $350^{\circ} \mathrm{C}$. This is related to the fact that the deformation degree of the alloy is different with different extrusion temperatures. When the extrusion temperature is lower, the deformation degree of the alloy is larger, and the grain size is smaller. Previous studies [27-29] pointed out that in Mg alloys, there is a close relationship between material strength and grain size, which satisfies the Hall-Petch formula:

$$
\sigma_{s}=\sigma_{0}+K d^{-1 / 2}
$$

where $\sigma_{s}$ is the yield strength, $\sigma_{0}$ is the frictional resistance of dislocation movement in a single crystal, $K$ is a constant related to the material, and $d$ is the average grain size. It can be seen that the yield strength of $\mathrm{Mg}$ alloy has a linear relationship with $d^{-1 / 2}$ [28], that is, the yield strength increases with the decrease in grain size. In addition, Zhang et al. [30,31] also pointed out that grain refinement can increase the number of dislocation motion disorders and reduce the length of dislocation groups inside the grain, resulting in an increase in the yield strength of Mg alloys. Figure 12 shows kernel average misorientation (KAM) mapping of the transition region of MSAZ-320 and MSAZ-350. It can be seen that the dislocation density of the alloy at $320^{\circ} \mathrm{C}$ is significantly higher than that at $350{ }^{\circ} \mathrm{C}$ through the dislocation maps of the transition region at two kinds of extrusion temperatures. That is, when the extrusion temperature is lower, the strength of the alloy is higher.
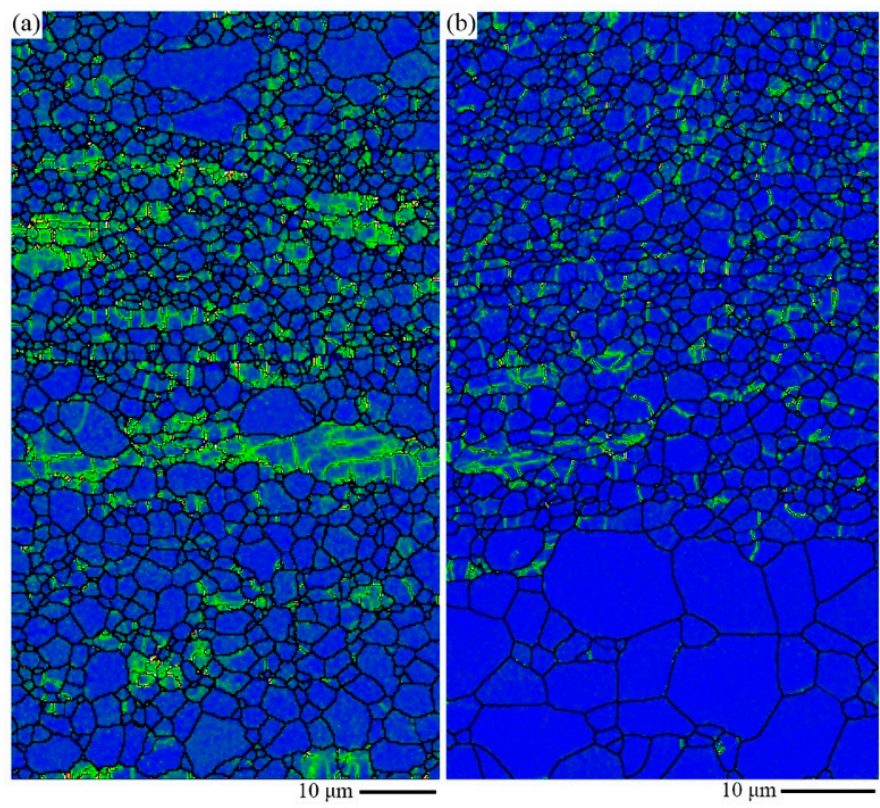

Figure 12. KAM mapping of the transition region of (a) MSAZ-320 and (b) MSAZ-350. 
However, the elongation of MS alloys obtained at $320^{\circ} \mathrm{C}$ is lower than that obtained at $350^{\circ} \mathrm{C}$. This is mainly related to the texture of the alloy. With the increase in extrusion temperature, the basal poles of MS deflected towards ED, and finally a double peaked basal texture occurred, which is beneficial to improving the fracture elongation of the alloy [32]. The elongation of the MSAZ alloy obtained at $320^{\circ} \mathrm{C}$ is lower than that of MSAZ alloy obtained at $350{ }^{\circ} \mathrm{C}$. This is mainly related to the distribution of microstructure, which will be explained in detail in the next section.

\subsubsection{Effect of AZ31 Surface Fine Layer on Mechanical Properties}

The mechanical properties of the Mg-Sc alloy with an AZ31 surface fine-grain layer are better than those without the AZ31 surface fine-grain layer at different extrusion temperatures. On the one hand, the surface AZ31 improves the strength of Mg-Sc alloy. Figure 6 shows that AZ31 at both extrusion temperatures has a relatively fine grain size on the surface, which can improve the strength of the alloy through fine-grain strengthening. It can be seen from the dislocation map of the transition region at two extrusion temperatures that the dislocation density of the AZ31 layer is significantly higher than that of $\mathrm{Mg}-1 \mathrm{Sc}$ alloy, which is also conducive to the improvement of alloy strength. In addition, Figure 13 depicts the distribution maps of Schmid Factor (SF) for the basal slip of the alloys. It shows that the average SF of the surface fine-grain layer, the transition layer, and the core layer is $0.22,0.18$, and 0.21 , respectively, at $320^{\circ} \mathrm{C}$. It is difficult to distinguish the intensity characteristics of the three regions from the distribution of SF. When extruded at $350^{\circ} \mathrm{C}$, the $\mathrm{SF}$ of the surface region reaches a peak in the range of $0-0.2$, and a lower SF is continuously distributed in the range of $0.2-0.4$. The SF of the core region is intermittently distributed with low SF in the range of $0-0.2$, and reaches the peak in the range of $0.2-0.5$. The average $\mathrm{SF}$ increased from 0.13 to 0.27 from the surface region to the core region. The lower SF is not conducive to start the base slip and the improvement of the yield strength. Therefore, this is also one of the reasons why the surface AZ31 improves the strength of $\mathrm{Mg}-\mathrm{Sc}$ alloy.

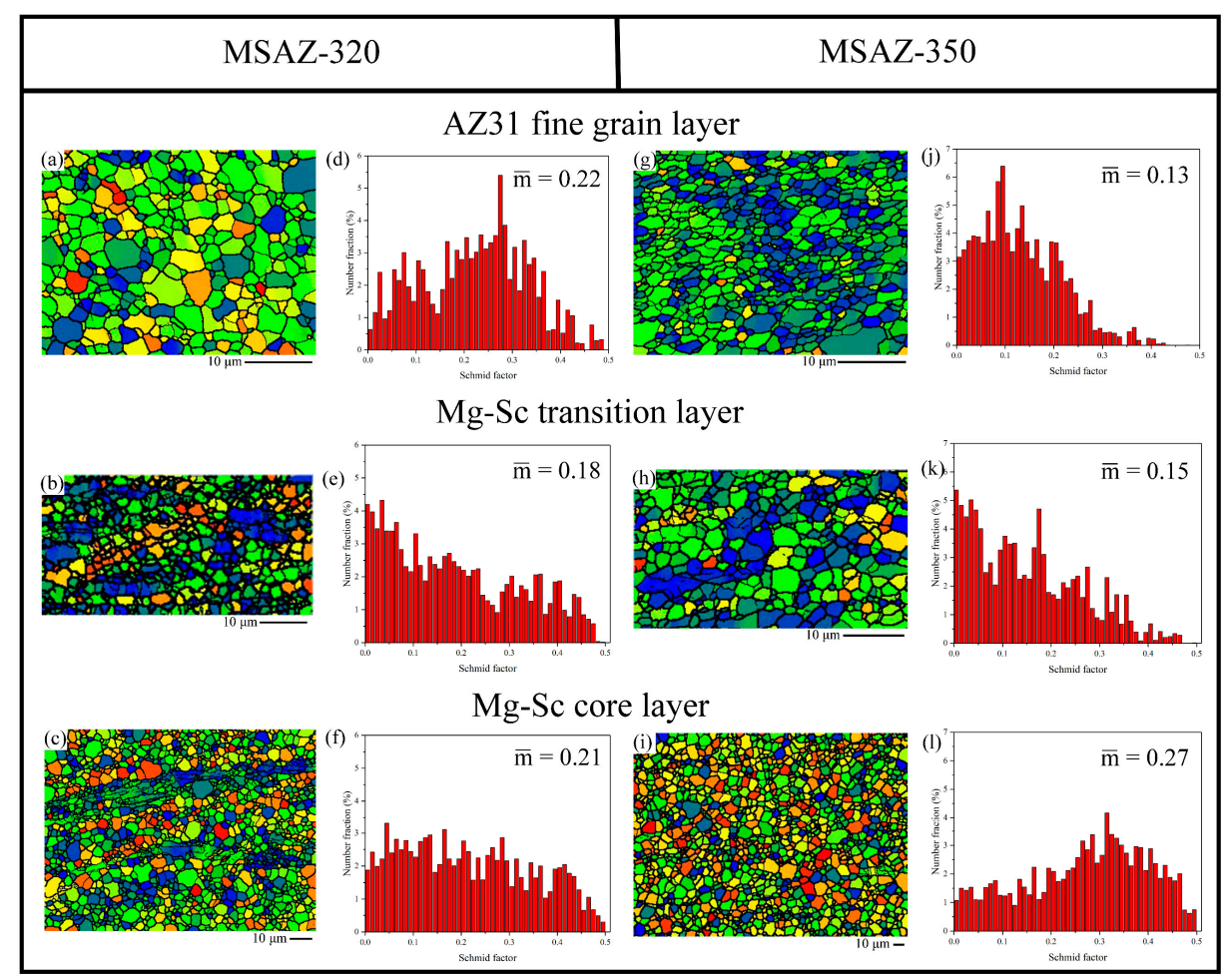

Figure 13. Quantitative analysis of $(0001) /<11-20>$ basal slip Schmid factor (SF) of (a,d) surface fine-grain layer, $(\mathbf{b}, \mathbf{e})$ transition layer, and $(\mathbf{c}, \mathbf{f})$ core layer of MSAZ-320. Quantitative analysis of $(0001) /<11-20>$ basal slip Schmid factor (SF) of $(\mathbf{g}, \mathbf{j})$ surface fine-grain layer, $(\mathbf{h}, \mathbf{k})$ transition layer, and $(\mathbf{i}, \mathbf{l})$ core layer of MSAZ-350. 
On the other hand, the surface AZ31 fine-grain layer also improves the elongation of $\mathrm{Mg}-\mathrm{Sc}$ alloy. Besides the texture composition and grain size, the distribution of the microstructure is also an important parameter affecting the strength and plasticity of $\mathrm{Mg}$ alloys. Research $[33,34]$ shows that the construction of gradient structure in metal materials can effectively inhibit the early deformation localization of metal in the process of plastic deformation, alleviate the internal stress concentration, and hinder the occurrence of cracks, so as to achieve a better strength plastic ratio. Therefore, the surface AZ31 fine-grain layer is beneficial to improving the mechanical properties of $\mathrm{Mg}-\mathrm{Sc}$ alloy.

\section{Conclusions}

The effect of an AZ31 surface fine-grain layer on the microstructure and mechanical properties of $\mathrm{Mg}-\mathrm{Sc}$ alloy were investigated. It was found that:

(1) AZ31/Mg-Sc composites with gradient grain structure were prepared by hot extrusion. The thickness of AZ31 accounts for $15 \%$ and $12 \%$ of the composition of the whole alloy when extruded at $320^{\circ} \mathrm{C}$ and $350{ }^{\circ} \mathrm{C}$, respectively;

(2) The nanoscale hardness value of $\mathrm{Mg}-1 \mathrm{Sc}$ alloy is increased more than two times through fine-grain strengthening and solution strengthening of the surface AZ31 fine-grain layer;

(3) The surface AZ31 fine-grain layer improves the strength of the Mg-1Sc alloy through fine-grain strengthening and dislocation strengthening, and increases the elongation by improving the distribution of microstructure;

(4) Different extrusion temperatures have different control effects on the microstructure of the AZ31/Mg-Sc composites. In this paper, the alloy has a more obvious gradient microstructure when extruded at $350{ }^{\circ} \mathrm{C}$.

Author Contributions: Conceptualization, C.Z.; methodology, C.Z. and Y.Z.; validation, G.W. and L.W.; formal analysis, T.H. and G.H.; investigation, Y.Z. and G.W.; data curation, C.P. and J.H.; writing-original draft preparation, C.Z. and Y.Z.; funding acquisition, C.P.; project administration, C.Z. All authors have read and agreed to the published version of the manuscript.

Funding: This work was supported by the National Natural Science Foundation of China (Grant No. 51905366), the China Postdoctoral Science Foundation (Grant No. 2021M692626), the Project for Chongqing University Innovation Research Group of Chongqing Education Committee (Grant No. CXQT19008), the Chongqing Talent Plan for Innovation and Entrepreneurship Demonstration Team (Grant No. CQYC201903243), the S\&T Project of Science and Technology Bureau of Bishan District in Chongqing (Grant No. Bskj20200011), the Science and Technology Research Program of Chongqing Municipal Education Commission (Grant No. KJQN201801419).

Institutional Review Board Statement: Not applicable.

Informed Consent Statement: Not applicable.

Data Availability Statement: Not applicable.

Conflicts of Interest: The authors declare no conflict of interest.

\section{References}

1. Chen, X.; Wang, L.; Xiao, R.; Zhong, X.; Huang, G.; Liu, Q. Comparison of annealing on microstructure and anisotropy of magnesium alloy AZ31 sheets processed by three different routes. J. Alloys Compd. 2014, 604, 112-116. [CrossRef]

2. Han, T.; Zou, J.; Ma, L.; Huang, G.; Che, C.; Jia, W.; Wang, L.; Pan, F.; Zhang, Y. Microstructure Evolution and Mechanical Properties of Mg-1.5Zn-0.2Ca-0.2Ce Alloy Processed by Accumulated Extrusion Bonding. JOM 2020, 72, 2597-2602. [CrossRef]

3. Jia, W.; Ma, L.; Le, Q.; Zhi, C.; Liu, P. Deformation and fracture behaviors of AZ31B Mg alloy at elevated temperature under uniaxial compression. J. Alloys Compd. 2019, 783, 863-876. [CrossRef]

4. Zhang, C.; Wu, L.; Zhao, Z.; Huang, G.; Jiang, B.; Atrens, A.; Pan, F. Effect of the Al-Si eutectic on the microstructure and corrosion behavior of the single-phase Mg alloy Mg-4Li. J. Magnes. Alloys 2021, 9, 1339-1348. [CrossRef]

5. Wang, X.J.; Xu, D.K.; Wu, R.Z.; Chen, X.B.; Peng, Q.M.; Jin, L.; Xin, Y.C.; Zhang, Z.Q.; Liu, Y.; Chen, X.H.; et al. What is going on in magnesium alloys? J. Mater. Sci. Technol. 2018, 34, 245-247. [CrossRef]

6. Zhang, H.; Liu, Y.; Fan, J.; Roven, H.J.; Cheng, W.; Xu, B.; Dong, H. Microstructure evolution and mechanical properties of twinned AZ31 alloy plates at lower elevated temperature. J. Alloys Compd. 2014, 615, 687-692. [CrossRef] 
7. Han, T.; Zou, J.; Huang, G.; Ma, L.; Che, C.; Jia, W.; Wang, L.; Pan, F. Improved strength and ductility of AZ31B Mg alloy sheets processed by accumulated extrusion bonding with artificial cooling. J. Magnes. Alloys 2021, 9, 1715-1724. [CrossRef]

8. Wei, Y.; Li, Y.; Zhu, L.; Liu, Y.; Lei, X.; Wang, G.; Wu, Y.; Mi, Z.; Liu, J.; Wang, H. Evading the strength-ductility trade-off dilemma in steel through gradient hierarchical nanotwins. Nat. Commun. 2014, 5, 1-8. [CrossRef] [PubMed]

9. Fang, T.H.; Tao, N.R.; Lu, K. Tension-induced softening and hardening in gradient nanograined surface layer in copper. Scripta. Mater. 2014, 77, 17-20. [CrossRef]

10. Fang, T.H.; Li, W.L.; Tao, N.R.; Lu, K. Revealing extraordinary intrinsic tensile plasticity in gradient nano-grained copper. Science 2011, 331, 1587-1590. [CrossRef]

11. Meng, X.; Duan, M.; Luo, L.; Zhan, D.; Jin, B.; Jin, Y.; Rao, X.-X.; Liu, Y.; Lu, J. The deformation behavior of AZ31 Mg alloy with surface mechanical attrition treatment. Mater. Sci. Eng. A 2017, 707, 636-646. [CrossRef]

12. Rai, P.K.; Pandey, V.; Chattopadhyay, K.; Singhal, L.K.; Singh, V. Effect of Ultrasonic Shot Peening on Microstructure and Mechanical Properties of High-Nitrogen Austenitic Stainless Steel. J. Mater. Eng. Perform. 2014, 23, 4055-4064. [CrossRef]

13. Dai, S.; Zhu, Y.; Huang, Z. Microstructure evolution and strengthening mechanisms of pure titanium with nano-structured surface obtained by high energy shot peening. Vacuum 2016, 125, 215-221. [CrossRef]

14. Chen, L.; Yuan, F.; Jiang, P.; Xie, J.; Wu, X. Mechanical properties and deformation mechanism of Mg-Al-Zn alloy with gradient microstructure in grain size and orientation. Mater. Sci. Eng. A 2017, 694, 98-109. [CrossRef]

15. Peng, J.; Zhang, Z.; Guo, P.; Liu, Z.; Li, Y.; Zhou, W.; Wu, Y. The effect of surface mechanical attrition treatment on texture evolution and mechanical properties of AZ31 magnesium alloy. Mater. Charact. 2019, 148, 26-34. [CrossRef]

16. Jamalian, M.; Field, D.P. Effects of shot peening parameters on gradient microstructure and mechanical properties of TRC AZ31. Mater. Charact. 2019, 148, 9-16. [CrossRef]

17. Kula, A.; Silva, C.J.; Niewczas, M. Grain size effect on deformation behaviour of Mg-Sc alloys. J. Alloys Compd. 2017, 727, 642-657. [CrossRef]

18. Mordike, B.; Stulikova, I.; Smola, B. Mechanisms of creep deformation in Mg-Sc-based alloys. Metall. Mater. Trans. A 2005, 36, 1729-1736. [CrossRef]

19. Silva, C.J.; Kula, A.; Mishra, R.K.; Niewczas, M. The effect of Sc on plastic deformation of Mg-Sc binary alloys under tension. J. Alloys Compd. 2018, 761, 58-70. [CrossRef]

20. Zhang, C.; Wu, L.; Liu, H.; Huang, G.; Jiang, B.; Atrens, A.; Pan, F. Microstructure and corrosion behavior of Mg-Sc binary alloys in 3.5 wt.\% NaCl solution. Corros. Sci. 2020, 174, 108831. [CrossRef]

21. Fan, X.; Chen, L.; Chen, G.; Zhao, G.; Zhang, C. Joining of 1060/6063 aluminum alloys based on porthole die extrusion process. J. Mater. Process. Technol. 2017, 250, 65-72. [CrossRef]

22. Li, N.; Huang, G.; Xin, R.; Liu, Q. Influence of extrusion ratio on microstructure and texture developments of high-temperature extruded AZ31 Mg alloy. Sci. China Technol. Sci. 2012, 55, 490-495. [CrossRef]

23. Han, T.; Huang, G.; Deng, Q.; Wang, G.; Jiang, B.; Tang, A.; Zhu, Y.; Pan, F. Grain refining and mechanical properties of AZ31 alloy processed by accumulated extrusion bonding. J. Alloys Compd. 2018, 745, 599-608. [CrossRef]

24. Han, T.; Huang, G.; Ma, L.; Wang, G.; Wang, L.; Pan, F. Evolution of microstructure and mechanical properties of AZ31 Mg alloy sheets processed by accumulated extrusion bonding with different relative orientation. J. Alloys Compd. 2019, 784, 584-591. [CrossRef]

25. Han, L.; Hu, H.; Northwood, D.O.; Li, N. Microstructure and nano-scale mechanical behavior of $\mathrm{Mg}-\mathrm{Al}$ and $\mathrm{Mg}-\mathrm{Al}-\mathrm{Ca}$ alloys. Mater. Sci. Eng. A 2008, 473, 16-27. [CrossRef]

26. Somekawa, H.; Schuh, C.A. Effect of solid solution elements on nanoindentation hardness, rate dependence, and incipient plasticity in fine grained magnesium alloys. Acta Mater. 2011, 59, 7554-7563. [CrossRef]

27. Zhang, L.; Wang, Q.; Liao, W.; Guo, W.; Ye, B.; Li, W.; Jiang, H.; Ding, W. Effects of cyclic extrusion and compression on the microstructure and mechanical properties of AZ91D magnesium composites reinforced by SiC nanoparticles. Mater. Charact. 2017, 126, 17-27. [CrossRef]

28. Song, B.; Xin, R.; Chen, G.; Zhang, X.; Liu, Q. Improving tensile and compressive properties of magnesium alloy plates by pre-cold rolling. Scripta. Mater. 2012, 66, 1061-1064. [CrossRef]

29. Yin, S.M.; Wang, C.H.; Diao, Y.D.; Wu, S.D.; Li, S.X. Influence of Grain Size and Texture on the Yield Asymmetry of Mg-3Al-1Zn Alloy. J. Mater. Sci. Technol. 2011, 27, 29-34. [CrossRef]

30. Zhang, H.; Huang, G.; Wang, L.; Roven, H.J.; Xu, Z.; Pan, F. Improved ductility of magnesium alloys by a simple shear process followed by annealing. Scripta. Mater. 2013, 69, 49-52. [CrossRef]

31. Zhang, H.; Huang, G.; Wang, L.; Li, J. Improved formability of Mg-3Al-1Zn alloy by pre-stretching and annealing. Scripta. Mater. 2012, 67, 495-498. [CrossRef]

32. Wang, G.; Huang, G.; Huang, Y.; Zhang, C.; Pan, F. Achieving High Ductility in Hot-Rolled Mg-xZn-0.2Ca-0.2Ce Sheet by Zn Addition. JOM 2020, 72, 1607-1618. [CrossRef]

33. Lu, K. Making strong nanomaterials ductile with gradients. Science 2014, 345, 1455-1456. [CrossRef] [PubMed]

34. Wu, X.; Jiang, P.; Chen, L.; Zhang, J.; Yuan, F.; Zhu, Y. Synergetic strengthening by gradient structure. Mater. Res. Lett. 2014, 2, 185-191. [CrossRef] 